\title{
Adherence to antiretroviral therapy in a context of universal access, in Rio de Janeiro, Brazil
}

\author{
R. H. REMIEN ${ }^{1}$, F. I. BASTOS ${ }^{2}$, V. TERTO JNR. ${ }^{3}$, J. C. RAXACH ${ }^{3}$, \\ R. M. PINTO ${ }^{1}$, R. G. PARKER ${ }^{4,1,3}$, A. BERKMAN ${ }^{1,4}, \&$ M. A. HACKER ${ }^{2}$ \\ ${ }^{1}$ HIV Center for Clinical and Behavioral Studies, NY State Psychiatric Institute and Columbia University, New York, USA, \\ ${ }^{2}$ Department of Health Information, Center for Information in Science and Technology, the Oswald Cruz Foundation, Rio de \\ Faneiro, Brazil, ${ }^{3}$ Brazilian Interdisciplinary Association for AIDS, Rio de Faneiro, Brazil, and ${ }^{4}$ Department of Sociomedical \\ Sciences, Mailman School of Public Health, Columbia University, NY, USA
}

\begin{abstract}
Adherence is integral to improving and maintaining the health and quality of life of people living with HIV. Two-hundred HIV-positive adults recruited from teaching hospitals and non-governmental organizations (NGOs) in Rio de Janeiro City were assessed on socio-demographic factors, adherence to antiretroviral therapy (ART) and psychosocial factors hypothesized to be associated with ART. Predictors of non-adherence were analyzed using bivariate and multivariate analyses. Self-reported medication adherence was high $(82 \%$ had adherence $>90 \%)$. Non-adherence was associated with personal factors (i.e. sexual orientation, self-efficacy), physical factors (i.e. loss of appetite) and interpersonal factors (i.e. doctor-patient relationship). Adherence in Brazil is as good, if not better, than that seen in the US and western Europe, which is noteworthy since the sample was derived predominantly from public healthcare settings. It is possible that the connection to NGOs in Rio de Janeiro City played a helpful role in achieving high levels of adherence in this sample of people living with HIV and AIDS. Recommendations, based on study findings, include enhancing and sustaining supportive services for NGOs, promoting patient self-efficacy and behavioral skills for adherence, increasing social network support and having healthcare providers directly address patients' medication beliefs, attitudes and experience with side effects.
\end{abstract}

\section{Introduction}

\section{The Brazilian context}

Brazil has been recognized as a pioneer, among 'developing' nations, for its implementation of universal access to AIDS medicines. This policy dictates that every HIV-positive Brazilian citizen has the right to receive publicly subsidized AIDS drugs. This policy evolved as a result of several major historical events in Brazil, including the creation of a Unified National Health System in 1990s and the continual development of linkages between the Brazilian government and non-profit organizations (for a detailed account, see Berkman et al., 2005, Parker, 2003 and Teixeira, 2003).

In 1983, the AIDS programs established in São Paulo included prevention services and epidemiological surveillance and a strong connection with NGOs that focused on advocacy and human rights for HIV-infected people (Passareli \& Terto, 2003). These NGOs had a crucial role in the Brazilian response to the AIDS epidemic and they began to provide numerous psychosocial services all of which eventually became routine services in Brazil's unified health system. This sociopolitical endeavor has been described as a bottom-up approach to public health and used to explain the integral participation of NGOs in the development of the National AIDS Program in Brazil (Berkman et al., 2005). Starting in 1996-1997, Brazil began to distribute free combination antiretroviral therapies. By the end of 2001, nearly 113,000 individuals were receiving antiretroviral therapies through the Brazilian public health system (Vitória, 2003).

\section{Antiretroviral therapy and adherence}

In settings where ART is available, AIDS-related mortality and morbidity have been dramatically reduced (Mocroft et al., 2003; Palella et al., 1998; Sepkowitz, 2001). Although ART constitutes a major medical advancement in the clinical management of HIV, its success depends on strict adherence to prescribed regimens (Chesney et al., 1999; Paterson et al., 2000). Many studies have documented the relationship between adherence to ART and 
virologic, immunologic and clinical outcomes, including progression to AIDS, occurrence of opportunistic infections and survival, with $95 \%$ adherence identified as the 'gold standard' (Garcia de Olalla et al., 2002; Howard et al., 2002; McNabb, et al., 2001; Paterson et al., 2000; Wood et al., 2003).

Several studies in the US and Europe reveal that only a minority $(20-40 \%)$ of patients are able to achieve such high adherence levels. Adherence rates for ART, as measured by electronic monitoring, generally range from $50-80 \%$ (Arnsten et al., 2001; Bangsberg et al., 2001; Howard et al., 2002; Paterson et al., 2000; Remien et al., 2005). Before Brazil's implementation of universal access to AIDS medicines, it had been hypothesized that this level of adherence could not be achieved in a 'developing' nation. Initial resistance to this policy from UN agencies, the World Bank and other political forces did not account for the fact the Brazil had successfully addressed several public health issues, including tuberculosis and other opportunistic infections (Teixeira, 2003). Unlike initial predictions, studies have suggested that adherence levels among adult populations in Brazil are comparable to those seen in the US and Europe (Hofer et al., 2004; Pinheiro et al., 2002).

There have been many studies examining factors associated with adherence to ART in the US and European countries where treatment has been available since the mid-1990s. Generally, these factors can be categorized into: (1) individual factors, such as substance use, age, attitudes towards treatment and psychological characteristics, (2) medication characteristics, such as dosing complexity, and number of pills or food requirements, (3) interpersonal characteristics, such as the doctor-patient relationship and other social supports and (4) the general system within which care is administered (Chesney, 2000; Fogarty et al., 2002; Ickovics, 2002; Remien, 1998; Remien et al. 2003). Factors that are consistently related to non-adherence include side effects and depression, poor social support and patient-provider relations and attitudes such as mistrust and skepticism about treatment and medications. Other factors have been less consistently linked to poor adherence, including gender, ethnicity, age, education, lack of stable housing, anxiety, regimen complexity and substance use (Catz et al., 2000; Gifford et al., 2000; Mehta et al., 1997).

There are very few studies in the literature that have identified factors associated with adherence in the Brazilian context. Some studies conducted in Brazil have shown that adherence self-efficacy (belief in one's ability to adhere), frequency of dosing, prescription literacy and medication beliefs were related to adherence or response to therapy outcomes (Hofer et al., 2004; Pinheiro et al., 2002).
Another study found that forgetfulness, alcohol use and misunderstanding were reasons given for nonadherence by patients in an AIDS outpatient clinic of a public teaching hospital in Brazil (Brigido et al., 2001).

Given the importance of understanding how individuals in 'developing' countries will manage their adherence to antiretroviral treatments, more studies are needed to observe adherence outcomes and factors associated with adherence in these settings. The Brazilian context of universal access to ART and the historical involvement of NGOs in the care of HIV-positive individuals provides an excellent opportunity for studying the factors that contribute to adherence in a 'developing' nation. Findings from such studies will have important implications for potential outcomes of widespread distribution of antiretroviral therapy in limited resource regions of the world, including Africa, Asia, Latin America and eastern Europe.

In a cross-sectional interview survey we examined self-reported adherence and a range of background and psychosocial factors that have been observed to influence medication adherence in other studies in the US and Europe. We conducted this study with men and women on ART in the unified public healthcare system in Rio de Janeiro, using a nonrandom convenience sample recruited in teaching hospitals of the Brazil Unified National Health System and NGOs. For the purposes of this report we proposed the following questions: (1) What are medication adherence levels among men and women receiving ART in public health settings in Rio de Janeiro? (2) What are the most common reasons given for non-adherence (e.g. missed doses)? (3) What background, health, healthcare and psychosocial factors are associated with adherence/nonadherence?

\section{Methods}

Participants

The study assessed a convenience sample of 200 individuals living with HIV/AIDS, recruited from two large teaching hospitals and several NGOs where HIV-positive adults receive supportive services in Rio de Janeiro. Most of these NGOs are located in the southern parts of the city and included: the group Pela VIDDA (the Valorization, Integration and Dignity of People with AIDS); the group GATAHI (Group for Support in the Treatment of AIDS in the Hospital de Ipanema); the gay group Arco-lris (Rainbow); and the RNP (National Web of People Living with HIV/AIDS). These teaching hospitals and NGOs have long standing relationships with the populations most affected by 
the HIV epidemic (gay men and racial minorities) and also have a history of providing supportive services to people living with HIV/AIDS. These services include workshops on adherence to AIDS medicines, social support groups and counseling on myriad issues. Therefore, these locations were chosen for their core roles in the delivery of care and psychosocial support to people living with HIV/ AIDS in Rio de Janeiro. To be eligible, participants had to be 18 years of age, HIV-positive and currently on any antiretroviral therapy (determined by selfreport).

\section{Procedures}

All research activities were reviewed and approved by the institutional review boards at the New York State Psychiatric Institute, the Brazil National IRB (CONEP) and the Institute of Psychiatry of Rio de Janeiro Federal University prior to implementation. Recruitment strategies included flyers posted at each recruitment site, announcements on each of the NGOs' websites and local papers. Health workers in all participating sites also actively recruited participants during their visits for supportive services. After receiving permission from clinic and NGO staff, study team members approached potential participants in the clinic waiting room or lounge gathering areas of the NGOs. Many respondents also referred friends and acquaintances to the study.

The study team distributed a written description, in Portuguese, of the study and explained to participants the purpose and procedures of the study. Portuguese was the only language used because all participants spoke and read Portuguese. If the potential participant was interested and met the study's inclusion criteria, he/she was asked to sign a consent form after having the opportunity to ask any questions he/she had about the study. The consent form, as well as all research measurements used in this study, were written to accommodate an eighth grade reading level. However, all participants had completed middle school. The consent process included explaining to participants the risks and benefits of the study and answering any questions they may have had. Following the consent process, an appointment was made for the cross-sectional interview. Although all participants in this study reported having access to medical and social services, after the interview each participant was given a list of places where they could access medical and social services and also a telephone number to call in case they felt distressed due to the interview.

Five trained interviewers (health workers in the NGOs involved in the study) administered all interviews in a private location. These professionals had college degrees in nursing, psychology or social work. They were trained in issues related to HIV biology and transmission, medication adherence and ethics of research. The assessment included both interview-administered questions and self-report questionnaires. All measurements that were developed originally in English were translated and adapted by two Brazilian professionals with expertise in HIV/AIDS. All materials were in Portuguese. Interviewers were available to answer any questions while participants filled out the self-reports. Interviews lasted 60-90 minutes; participants volunteered their time and did not receive any monetary compensation.

\section{Measures}

Demographics/background. Detailed background and demographic data included items such as respondent age, race/ethnicity, gender, sexual orientation, relationship status, educational level, employment status, income, living arrangements, treatment history, source of medical care and length of HIV diagnosis.

Health and treatment factors. Self-reported CD4 count, viral load, time since HIV diagnosis and length of time on current ART regimen were assessed. Number of doses per day and total number of pills prescribed per day were assessed as indicators of regimen complexity. Symptoms were assessed based on the AIDS Clinical Trials Group symptom checklist adapted by asking respondents currently taking anti-retroviral medication whether or not endorsed items are due to their anti-retroviral medications (alpha $=0.89)$ (Justice et al., 2001).

Positive patient-provider interactions. Adapted from previous studies (Stall et al., 1996), we administered an 8-item scale to assess patients' perceptions of positive interactions with their providers. Respondents were asked how often certain things occurred during recent contacts with healthcare providers, such as discussing side effects and other medication problems, getting providers to really listen to concerns and feeling helped by their providers. Response choices were 'never' $=0$, 'some of the time' $=1$, 'most of the time' $=2$ and 'every time' $=$ 3. For these analyses, scores on each item are averaged for each respondent with higher scores indicating more positive provider interactions $($ alpha $=0.89)$.

Adherence self-efficacy. A 12-item scale was used to assess patient confidence to carry out important treatment-related behaviors, for example: how confident have you been that you can: (1) stick to your treatment plan even when side effects begin to interfere with daily activities, (2) integrate your 
treatment into your daily routine, (3) stick to your treatment schedule even when your daily routine is disrupted and (4) continue with your treatment even when you are feeling discouraged about your health. Response anchors ranged from 'cannot do it at all' $=$ 1 to 'certain you can do it' $=10$. Scores on each item were averaged for each respondent with higher scores indicating higher adherence self-efficacy $($ alpha $=0.91)$ (Chesney et al., 1999).

Medication adherence. Recent self-reported antiretroviral medication adherence was assessed over a three-day period using an adherence survey developed for use in AIDS Clinical Trials (Chesney et al., 2000). Respondents were asked to indicate how many antiretroviral pills they had skipped during each of the previous three days. This measure has been used widely with diverse samples and the short term recall period has been associated with long term clinical outcomes. Adherence was assessed only for those ART medications that were reported in the adherence section of the interview. For the present study, we calculated percent adherence based on number of pills taken divided by the number of pills respondents reported being expected to take. Respondents were classified as having achieved less than $90 \%$ adherence versus $90 \%$ or higher adherence, consistent with current literature on minimum levels of adherence to achieve HIV viral suppression and clinical benefit (Garcia de Olalla et al., 2002; Paterson et al., 2000). Participants were also asked about missed medical appointments during the past three months.

Social support. The global score on the Social Provisions Scale (SPS) (Cutrona, 1989) was used to assess level, type and perceived satisfaction with social supports from one's social network. This 24-item scale breaks down into subscales measuring six dimensions of social support. The six provisions include guidance (advice or information), reliable alliance (assurance that others can be counted on in times of stress), reassurance of worth (recognition of one's competence), attachment (emotional closeness), social integration (a sense of belonging to a group of friends) and opportunity for nurturance (providing assistance to others) (alpha $=0.70$ ).

Substance use. Frequency and amount of use in the past three months of alcohol and illicit substances was assessed including marijuana, heroin (or other opiates), cocaine, methamphetamine (or other stimulants), barbiturates, poppers and 'club drugs' (e.g. MDMA, ecstasy, ketamine). History of drug injection in the past year was also assessed and classified dichotomously (yes/no).
Attitudes about medications. Individual Likert-scaled items covered beliefs about concerns and necessity of treatment, attributions of side effects of treatment, beliefs about treatment outcomes and the impact of medication on quality of life.

\section{Analytic strategy}

Data were entered into IMPS (Integrated Microcomputer Processing System, Bureau of Census, US) databank and analyzed with SPSS. Following Cohen and Cohen (1983), diagnostic tests were used to identify sources of regression inadequacy, such as scatter plots for curvilinearity and outliers, the F-test for heteroscedasticity and correlation matrices for multicolinearity. Appropriate corrections were made, including the dichotomization of variables that severely violated a normal distribution and the omission of highly correlated independent variables from regression analyses. Bivariate analyses of the putative associations of the outcome $(90 \%$ adherence to ART regimens) and sociodemographic, behavioral and clinical covariates were carried out, using contingency tables statistics or $t$-test for means. Only variables that correlated with the outcome were included in subsequent analyses. For this reason, we present only those variables that were significantly $(p<0.05)$ related to the adherence outcome. For multivariate analyses we entered gender, age and the variables that were hypothesized to be associated with adherence (based on prior research) and found to be associated with our primary outcome at the level of 0.1 , with subsequent backward elimination.

\section{Results}

Socio-demographics

Table I presents socio-demographic information for the sample of 200 participants; 199 were Brazilian and one was Portuguese and all were living in the Rio de Janeiro metropolitan area. Most were young/ middle-aged men, with a male:female ratio $(2.5: 1)$ roughly similar to the figures for Brazilian people living with HIV/AIDS (Brazilian Ministry of Health, 2005). Most participants classified themselves as black/mulatto $(52.5 \%)$ or white $(44.5 \%)$. The majority were single $(62 \%)$ and most were living with other(s) $(76.5 \%)$. Fifty percent of the sample identified as heterosexual, $39.5 \%$ as homosexual and $10.5 \%$ as bisexual. There was a wide range in educational background and employment status with the majority $(71 \%)$ falling within the middle to lower socio-economic class. Here, we used the standard Brazilian definition of social class, also used in Brazil's national census, based on the total value 
Table I. Socio-demographic characteristics of the 200 interviewees. Rio de Janeiro, 2000-2001.

\begin{tabular}{|c|c|}
\hline Socio-demographic information & Frequency $(\%)$ \\
\hline \multicolumn{2}{|l|}{ Sex } \\
\hline Male & 71 \\
\hline Female & 29 \\
\hline \multicolumn{2}{|l|}{ Race } \\
\hline Mulatto/black & 52.5 \\
\hline White & 44.5 \\
\hline Other & 3 \\
\hline \multicolumn{2}{|l|}{ Marital Status } \\
\hline Single & 62 \\
\hline Legally married/living as married & 18.5 \\
\hline Widowed/legally separated/divorced & 19.5 \\
\hline \multicolumn{2}{|l|}{ Years of education } \\
\hline Up to 8 years & 23.5 \\
\hline $8-12$ years & 22.5 \\
\hline College & 35 \\
\hline Graduate & 19 \\
\hline \multicolumn{2}{|l|}{ Religion } \\
\hline Catholic & 37.5 \\
\hline Protestant & 15.5 \\
\hline Spiritualist & 14.5 \\
\hline Afro-Brazilian cult & 5 \\
\hline None & 16.5 \\
\hline Other & 11 \\
\hline \multicolumn{2}{|l|}{ Occupation } \\
\hline Regularly employed (private/public companies) & 21.5 \\
\hline Self-employed & 12.5 \\
\hline Social insurance & 24.5 \\
\hline Unemployed & 13.5 \\
\hline Other (e.g. housekeepers) & 28 \\
\hline \multicolumn{2}{|l|}{ Social class } \\
\hline A/B (upper/upper-middle) & 29 \\
\hline $\mathrm{C} / \mathrm{D} / \mathrm{E}$ (middle/lower-middle/lower) & 71 \\
\hline \multicolumn{2}{|l|}{ Living alone } \\
\hline Yes & 23.5 \\
\hline No & 76.5 \\
\hline Age (mean, SD) (Range: 21-63) & $38.2(9)$ \\
\hline
\end{tabular}

of a family's goods (National Institute of Geography and Statistics, 2005). There were no eligible potential participants who refused to take part in the study once they had expressed interest in the study and had the study described to them. Of those potential participants who were approached in the clinic waiting rooms or lounges of the NGOs only $2 \%$ refused participation (due to lack of time).

\section{Adherence}

Fourteen percent reported less than $90 \%$ adherence for the past three days compared to $81.5 \%$ who reported greater than $90 \%$ adherence $(4.5 \%$ had missing data). Twenty-three participants (11.5\%) reported they had skipped pills during the last weekend and $73(36.5 \%)$ stated they had never skipped pills since they had been on antiretroviral therapy.

\section{Reasons for non-adherence}

A wide range of reasons for missed doses were endorsed with varying levels of frequency (see Table II), while for all reasons listed the majority response was 'never'. The most frequently endorsed reasons were related to changes in daily routine, forgetfulness and not having the medication, as well as having physical symptoms, including side-effects from the medicine. While less frequently endorsed, other reasons for non-adherence included the desire to maintain confidentiality, thinking that the medicines are harmful, or feeling depressed or unmotivated.

\section{Factors associated with adherence}

In bivariate analyses, adherence was associated with self-identified sexual orientation. Participants who identified themselves as 'heterosexual' were more likely to report missing pills than those self-defined as 'homosexual/gay'. There were no women who self-identified as homosexual/lesbian and we found no overall effect of gender on adherence. Nonadherence was also associated with difficulty in maintaining a treatment schedule when daily routine was disrupted, loss of appetite, missing medical appointments and perception of provider lacking concerns about one's health (see Table III). In the multivariate analysis, factors that remained significant were sexual orientation, difficulty in maintaining a treatment schedule even when daily routine was disrupted and loss of appetite (see Table IV). Heterosexuals were 2.7 times more likely to have less than $90 \%$ adherence. Participants who reported difficulty in maintaining a treatment schedule, as well as those who reported loss of appetite were, respectively 2.6 and 3.6 less likely to have adherence above $90 \%$.

\section{Discussion}

Overall, self-reported medication adherence was high in our sample, which is particularly noteworthy given that the sample was derived predominantly from public healthcare settings. However, it is not uncommon to find high levels of adherence when relying on self-report measures of medication-taking behavior since self-reports consistently overestimate adherence (Melbourne et al., 1999). Nevertheless, having used a self-report questionnaire that has been used widely in many other studies in many regions of the world, we found level of adherence in Brazil to be as good, if not better, than that seen in the US and western Europe. We hypothesize that given the historical moment of ART medication, free access in large scale in Brazil may have influenced high rates of adherence. This study took place only a few years 
Table II. Reasons for missing doses (last 3 months) among the 200 interviewees. Rio de Janeiro, 2000-2001.

\begin{tabular}{|c|c|c|c|c|}
\hline Queries & Never \% & Seldom \% & Sometimes $\%$ & Frequently $\%$ \\
\hline Away from home/travelling & 51.9 & 24.7 & 21.2 & 2.2 \\
\hline Busy with something else & 57 & 18.3 & 20.4 & 4.3 \\
\hline Change in routine & 65.2 & 16.3 & 16.3 & 2.2 \\
\hline Difficulty timing with meals & 81.3 & 5.5 & 11 & 2.2 \\
\hline Decided not to take & 76.1 & 12 & 9.7 & 2.2 \\
\hline The number of pills seems overwhelming & 88.2 & 2.2 & 7.4 & 2.2 \\
\hline Feeling well, no reason to take medicines & 81.8 & 3.2 & 11.8 & 3.2 \\
\hline To keep confidentiality & 74.2 & 10.8 & 14 & 1 \\
\hline Simply forgot & 45.2 & 32.3 & 19.3 & 3.2 \\
\hline Fell asleep & 65.6 & 15.1 & 18.3 & 1 \\
\hline Ran out of medicines & 78.3 & 12 & 8.7 & 1 \\
\hline Could not pick up the medicines & 82.8 & 7.5 & 9.7 & 0 \\
\hline To minimize side-effects & 75.3 & 7.5 & 10.7 & 6.5 \\
\hline The medicine seems to be harmful & 87.1 & 1.1 & 10.8 & 1 \\
\hline Felt sick & 63.0 & 15.2 & 12 & 9.8 \\
\hline Felt depressed/lack of motivation & 87 & 6.5 & 6.5 & 0 \\
\hline
\end{tabular}

after this policy had been in place and at a time that the mortality rate due to AIDS had decreased by $50 \%$. Also, participants may have been inclined to adhere to ART also because they had access to medical care and adjunct services that may have included adherence-related workshops and other services that provided the social support necessary to sustain adherence. While it was not tested in, nor the focus of this study, we believe one of the reasons for high levels of adherence can be attributed, at least in part, to the support services provided by the NGOs and teaching hospitals where participants in this study were receiving services. This should be examined directly in future studies. In the meantime, we believe it is appropriate to recommend that NGOs working with HIV-infected populations develop and strengthen programs that provide direct support for optimal medical adherence.

The most common reasons given for missed doses were similar to what has been seen in several other studies, mostly having to do with forgetting, having a busy schedule, being away from home and having physical symptoms. Thus, as many healthcare providers are aware, it is important to assist patients with pill reminders and enhance strategies to maintain their adherence when they are away from home, busy or experiencing changes in daily routines. Also, patients can benefit from support in handling the side effects of their medications and in alleviating all physical symptoms that can be associated with HIV disease.

Other reasons for non-adherence reported by some participants are of special concern since they may be linked to stigma (i.e. 'to keep confidentiality'), altered mood states (i.e. 'depressed'), an unwillingness to take the medicine (i.e. 'decided not to take') or a belief that the 'medicine seems to be harmful'. This suggests that patients could benefit from close monitoring and psychosocial support tailored to their specific needs. It is important to diagnose and treat depression, to address stigma and to directly address patients' beliefs,

Table III. Predictors of non-adherence (cut-point 90\% adherence) as shown by bivariate analyses $(n=200)$. Rio de Janeiro, $2000-2001$.

\begin{tabular}{|c|c|c|c|}
\hline Measure & Variable & OR & $95 \% \mathrm{CI}$ \\
\hline Demographics $(n=191)$ & Sexual orientation. (heterosexual versus homosexual/bisexual) & $2.48^{\star}$ & $(1.06-5.80)$ \\
\hline $\begin{array}{l}\text { Adherence self-efficacy } \\
\quad(n=191)\end{array}$ & $\begin{array}{l}\text { 'Stick to your treatment schedule even when your daily routine } \\
\text { is disrupted.' ('Slightly true'; 'Moderately true'; 'Definitely true' } \\
\text { versus 'Definitely false') }\end{array}$ & $2.62^{\star}$ & $(1.16-5.93)$ \\
\hline Physical symptoms $(n=180)$ & $\begin{array}{l}\text { Loss of appetite in the last month ('Yes, I had no appetite, but it } \\
\text { didn't bother me'; 'Yes, and it bothered me somewhat'; 'Yes, and } \\
\text { it bothered me a lot' versus 'No, it didn't change my appetite') }\end{array}$ & $2.74^{\star}$ & $(1.21-6.21)$ \\
\hline $\begin{array}{l}\text { Missed medical appointments } \\
\quad(n=180)\end{array}$ & $\begin{array}{l}\text { Missed medical appointments in the last } 3 \text { months ( }>0 \text { missed } \\
\text { appointments] versus } 0 \text { missed appointments) }\end{array}$ & $3.75^{\star \star}$ & $(1.46-9.59)$ \\
\hline $\begin{array}{l}\text { Positive patient-provider } \\
\quad \text { interactions }(n=188)\end{array}$ & $\begin{array}{l}\text { How frequently did your doctor seem concerned about your } \\
\text { health in the last 3months ('never'; 'sometimes'; 'most of the time' } \\
\text { versus 'always') }\end{array}$ & $2.90^{\star \star}$ & $(1.26-6.71)$ \\
\hline
\end{tabular}

Note: ${ }^{\star} p<0.05,{ }^{\star \star} p<0.01$. 
Table IV. Likelihood of non-adherence, as assessed by multiple logistic regression ( $n=200)$. Rio de Janeiro, $2000-2001$.

\begin{tabular}{|c|c|c|c|}
\hline Measure & Variable & Adjusted OR & $95 \% \mathrm{CI}$ \\
\hline Demographics $(n=191)$ & $\begin{array}{l}\text { Sexual orientation ('heterosexual'] versus } \\
\text { 'homosexual'/'bisexual') }\end{array}$ & $2.69^{\star}$ & $(1.08-6.66)$ \\
\hline Adherence self-efficacy $(n=191)$ & $\begin{array}{l}\text { Difficulty to tailoring therapeutic regimen to } \\
\text { daily routine ('Slightly true'; 'Moderately true'; } \\
\text { 'Definitely true' versus 'Definitely false') }\end{array}$ & $2.56^{\star}$ & $(1.07-6.14)$ \\
\hline Physical symptoms $(n=180)$ & $\begin{array}{l}\text { Loss of appetite in the last month ('Yes, I had no } \\
\text { appetite, but it didn't bother me'; 'Yes, and it bother } \\
\text { me someway'; 'Yes, and it bother me a lot' versus } \\
\text { 'No, it didn't change my appetite') }\end{array}$ & $3.56^{\star}$ & $(1.31-9.62)$ \\
\hline
\end{tabular}

Note: ${ }^{\star} p<0.05$.

attitudes and prejudices about antiretroviral medication in the context of providing comprehensive healthcare for people living with HIV.

In bivariate and multivariate analyses, non-adherence was associated with personal factors (i.e. sexual orientation, self-efficacy for fitting medication regimens into daily routines), physical factors (i.e. loss of appetite) and interpersonal factors (i.e. doctor-patient relationship, maintaining medical appointments). As happened in other countries, Brazilian gay men were strongly and deeply affected by the AIDS epidemic early on and gathered forces to protect themselves and to disseminate safer sex messages in their communities, with NGOs playing a key role in providing education and ongoing support. This may explain, in part, the higher level of adherence among this group. The other remaining factors that were associated with adherence are all open to intervention.

The study has some important limitations. This was a convenience sample recruited from public health clinics and NGOs providing a range of education and supportive services, compromising the generalizeability of the findings. The relatively high levels of adherence found in our sample may have been due, at least in part, to the level of motivation and support available to these participants in systems of care in Brazil. It is possible that these reference centers are more likely to deliver optimal care in comparison to the other health units belonging to the Brazilian ART dispensing network. A study coordinated by Nemes et al., (2004) in São Paulo, Brazil, showed there to be discrepancies between teaching hospitals and other outpatient units, with much better standards of care and management in the former compared to the latter. Nevertheless, convenience samples have been targeted by most studies aiming to assess adherence due to the heterogeneous nature of local health systems (Crepaz \& Marks, 2002). Another limitation, as stated earlier, is that adherence outcomes were determined by self-report, which is known to be higher than actual adherence. The restricted variance in both the independent variables and in the adherence scores in this sample may have prevented us from identifying other important factors that influence adherence in the Brazilian context. While acknowledging these study limitations and recognizing the need for ongoing research, we make the following clinical recommendations based on our study findings.

It is important to enhance patients' confidence in their ability to achieve and maintain high and consistent levels of adherence. This can be facilitated through social support from friends and family and supportive services offered in community organizations that are provided by health and mental health professionals. In fact, a recent study demonstrated an improvement in adherence by reinforcing partner-level support (Remien et al., 2005). Also, since the patient's perceived level of concern on the part of the doctor was associated with adherence, it may be important to foster improvements in patient-provider relationships. Interventions to improve provider relations may target the patient, the provider or both. For example, helping providers create an environment in which the patient feels heard and taken seriously may lead to greater self-efficacy in the patient, a higher maintenance of regular medical appointments, which ultimately may lead to better adherence.

Helping patients organize their daily routines so that medication adherence remains uninterrupted is likely to contribute to maintenance of high levels of adherence. This can be accomplished with concrete aids such as pill organizers, beepers and other types of reminders. Enhancing skills for problem solving will be necessary so that patients can address challenges to adherence in their daily lives. For example, if disclosure is an issue in particular contexts, patients can be helped to find ways of taking their medicine within designated time frames while still maintaining privacy.

Finally, doctors and ancillary healthcare providers must consistently address all physical symptoms experienced by people living with HIV and AIDS, 
including side effects from medication regimens; this needs to be done proactively, at the time of treatment initiation. Side effects should be anticipated and patients need to be equipped with strategies to handle the symptoms when they appear. Similarly, doctors and patients need to be able to talk directly and honestly about the patient's beliefs and attitudes towards the medications, including beliefs that doctors may feel are unfounded.

\section{Conclusion}

In spite of its limitations, this study lends additional support to findings that adherence to ART in 'developing' nations can be as good, if not better, than that seen in more developed nations where ART has been available for many years. These findings have important implications for potential outcomes of widespread distribution of antiretroviral therapy in resource-limited regions of the world. Given the high rates of adherence found in this study, it is recommended that policies be implemented to maintain the distribution of ART to all regions of Brazil and that medical and social services be in place where ART is available. We believe that high adherence throughout Brazil will largely depend on availability of adjunct services that will support adherence behavior over time. Similarly, reasons that patients give for non-adherence and the health and psychosocial factors that are associated with non-adherence, appear to not be radically different from that which has been seen in many other studies with people from many parts of the world. This study shows that there are a number of strategies that could be used in clinic and community-based settings that can enhance and maintain optimal levels of adherence for people accessing antiretroviral therapy, whether the context be private or public healthcare venues.

Since this study took place a few years after the implementation of free access to ART in Brazil, we note that participants may have been more inclined to adhere to ART precisely because of this historic moment. Future research will need to account for structural factors (e.g. policies, systems of ART distribution, lack of ART in remote regions of Brazil) that may influence adherence. Moreover, future research in this area will need to address issues such physical symptoms and body distortions due to prolonged use of ART. Since our sample had been taking medication for a relative short period of time, these issues were not addressed in this study.

\section{References}

Arnsten, J.H., Demas, P.A., Farzadegan, H., Grant, R.W., Gourevitch, M.N., Chang, C.J., et al. (2001). Antiretroviral therapy adherence and viral suppression in HIV-infected drug users: Comparison of self-report and electronic monitoring. Clinical Infectious Diseases, 33, 1417-1423.

Bangsberg, D.R., Perry, S., Charlebois, E., Clark, R.A., Robertson, M., Zolopa, A.R., et al. (2001). Non-adherence to highly active antiretroviral therapy predicts progression to AIDS. AIDS, 15, 1181-1183.

Berkman, A., Garcia, J., Muñoz-Laboy, M., Paiva, V., \& Parker, R. (2005). A critical analysis of the Brazilian response to HIV/ AIDS: Lessons learned for controlling and mitigating the epidemic in developing countries. American fournal of Public Health, 95, 1162-1172.

Brazilian Ministry of Health (2005). Epidemiologic Bulletin AIDST. Available at: http://www.aids.gov.br/final/dados/BOLETIM2.pdf

Brigido, L.F., Rodriguez, R., Casseb, J., Oliveira, D., Rossetti, M., Menezes, P., et al. (2001). Impact of adherence to antiretroviral therapy in HIV-1-infected patients at a university public service in Brazil. AIDS Patient Care STDS, 15, 587-593.

Catz, S.L., Kelly, J.A., Bogart, L.M., Benotsch, E.G., \& Mcailiffe, T.L. (2000). Patterns, correlates and barriers to medication adherence among persons prescribed new treatments for HIV disease. Health Psychology, 19, 124-133.

Chesney, M.A., Ickovics, J., Hecht, F.M., Sikipa, G., \& Rabkin, J. (1999). Adherence: A necessity for successful HIV combination therapy. AIDS, 13, S271-S278.

Chesney, M.A., Ickovics, J.R., Chambers, D.B., Gifford, J., Neidig, B., \& Zwickl, A.W. (2000). Self-reported adherence to antiretroviral medications among participants in HIV clinical trials: The AACTG adherence instruments. AIDS Care, 12, $255-266$.

Cohen, J., \& Cohen, P. (1983). Applied multiple regression/correlation analysis for the behavioral sciences (2nd edition). Hillside, New Jersey: Lawrence Erlbaum.

Crepaz, N., \& Marks, G. (2002). Towards an understanding of sexual risk behavior in people living with HIV: A review of social, psychological and medical findings. AIDS, 25, 135-149.

Cutrona, C.E. (1989). Ratings of social support by adolescents and adult informants: Degree of correspondence and prediction of depressive symptoms. Fournal of Personality and Social Psychology, 57, 723-730.

Fogarty, L., Roter, D., Larson, S., Burke, J., Gillespie, J., \& Levy, R. (2002). Patient adherence to HIV medication regimens: A review of published and abstract reports. Patient Education $\mathcal{E}$ Counseling, 46, 93-108.

Garcia De Olalla, P., Knobel, H., Carmona, A., Gnelar, A., Lopez-Colmes, J.L., \& Cayla, J.A. (2002). Impact of adherence and highly active antiretroviral therapy on survival in HIVinfected patients. Fournal of Acquired Immune Deficiency Syndromes, 30, 105-110.

Gifford, A.G., Bormann, J.E., Shively, M.J., Wright, B.C., Richman, D.D., \& Bozette, S.A. (2000). Predictors of self-reported adherence and plasma HIV concentrations in patients on multidrug antiretroviral regimens. Fournal of Acquired Immune Deficiency Syndromes, 23, 386-395.

Hofer, C.B., Schecter, M., \& Harrison, L.H. (2004). Effectiveness of antriretroviral therapy among patients who attend public $\mathrm{HIV}$ clinics in Rio de Janeiro, Brazil. Fournal of Acquired Immune Deficiency Syndromes, 36, 967-971.

Howard, A.A., Arnsten, J.H., Lo, Y., Vlahov, D., Rich, J.D., Schuman, P., et al. (2002). A prospective study of adherence and viral load in a large multi-center cohort of HIV-infected women. AIDS, 16, 2175-2182.

Ickovics, J.R., \& Meade, C.S. (2002). Adherence to HAART among patients with HIV: Breakthroughs and barriers. AIDS Care, 14, 309-318.

Justice, A. C., Holmes, W., Gifford, A. L., Rabeneck, L., Zackin, R., Sinclair, G., et al. (2001). Development and validation of a 
self-completed HIV symptom index. Fournal of Clinical Epidemiology, S77-S90.

Mcnabb, J., Ross, J.W., Abriola, K., Turley, C., Nightingale, C.H., $\&$ Nicolau, D.P. (2001). Adherence to highly active antiretroviral therapy predicts outcome at an inner-city human immunodeficiency virus clinic. Clinical Infectious Diseases, 33, 700-705.

Mehta, S., Moore, R.D., \& Graham, N.M. (1997). Potential factors affecting adherence with HIV therapy. AIDS, 11, $1665-1670$.

Melbourne, K.M., Geletko, S.M., Brown, S.L., Wiley-Lessne, C., Chase, S., \& Fisher, A. (1999). Medication adherence in patients with HIV infection: A comparison of two measurement methods. AIDS Reader, 9, 329-338.

Mocroft, A., Ledergerber, B., Katlama, C., Kirk, O., Reiss, P., D'arminio-Monforte, A., et al. (2003). Decline in the AIDS and death rates in the EuroSIDA study: An observational study. Lancet, 362, 22-29.

National Institute of Geography and Statistics (2005). Minimum Social Indicators. Available at: http://www.ibge.gov.br/

Nemes, A., Forster, T., \& Csanady, M. (2004). Antiretroviral therapy adherence in Brazil. AIDS, 18, (Suppl. 3), S15-S20.

Palella, F.J., Delaney, K.M., Moorman, A.C., Loveless, M.O., Fuhrer, J., Satten, G.A., et al. (1998). Declining morbidity and mortality among patients with advanced HIV infection. New England Fournal of Medicine, 338, 853-860.

Parker, R. (2003). Building the foundations for the response to HIV/AIDS in Brazil: The development of HIV/AIDS policy, 1982-1996. Debates on health issues, 27, 143-183. Rio de Janeiro: Centro Brasileiro de Estudos de Saúde.

Passareli, C.A., \& Terto, V.Jr. (2003). Non-governmental organizations and access to anti-retroviral treatments in Brazil. Debates on health issues, 27, 252-264. Rio de Janeiro: Centro Brasileiro de Estudos de Saúde.

Paterson, D.L., Swindells, S., Mohr, J., Brester, M., Vergis, E.N., \& Squier, C. (2000). Adherence to protease inhibitor therapy and outcomes in patients with HIV infection. Annals of Internal Medicine, 133, 21-30.
Pinheiro, C.A.T., De-Carvalho-Leite, J.C., Drachler, M.L., \& Silveira, V.L. (2002). Factors associated with adherence to antiretroviral therapy in HIV/AIDS patients: A cross-sectional study in southern Brazil. Brazilian fournal of Medical and Biological Research, 35, 1173-1181.

Remien, R.H. (1998). Adhering to HIV combination therapy: The role of the pharmacist. Pharmacy Times, 5, 28-37.

Remien, R.H., Stirratt, M.J., Dolezal, C., Dognin, J.S., Wagner, G.J., Carballo-Dieguez, A., et al. (2005). Couple-focused support to improve HIV medication adherence: A randomized controlled trial. AIDS, 19, 807-814.

Remien, R.H., Hirky, L., Johnson, M., Weinhardt, L., Whittier, D., \& Le, M.G. (2003). Adherence to medication treatment: A qualitative study of facilitators and barriers among a diverse sample of HIV-positive men and women in four US cities. AIDS and Behavior, 7, 61-72.

Sepkowitz, K. (2001). AIDS: The first 20 years. New England fournal of Medicine, 344, 1764-1772.

Stall, R., Hoff, C., Coates, T.J., Paul, J, Phillips, K.A., Ekstrand, M., et al. (1996). Decisions to get HIV tested and to accept antiretroviral therapies among gay/bisexual men: Implications for secondary prevention efforts. Fournal of Acquired Immune Deficiency Syndromes, 11, 151-160.

Teixeira, P. R. (2003). Universal access to AIDS medicines: The Brazilian response. Debates on health issues, 27, 184-191. Rio de Janeiro: Centro Brasileiro de Estudos de Saúde.

Vitória, M.A.V. (2003). The experience of providing universal access to ARV drugs in Brazil.

Debates on health issues, 27, 247-251. Rio de Janeiro: Centro Brasileiro de Estudos de Saúde.

Wood, E., Hogg, R.S., Yip, B., Harrigan, P.R., O'Shaughnessy, M.V., \& Montaner, J.S. (2003). Effect of medication adherence on survival of HIV-infected adults who start highly active antiretroviral therapy when the CD4 + cell count is 0.200 to $0.350 \times 10(9)$ cells/L. Annals of Internal Medicine, 139, 810816. 
Copyright of AIDS Care is the property of Routledge and its content may not be copied or emailed to multiple sites or posted to a listserv without the copyright holder's express written permission. However, users may print, download, or email articles for individual use. 
Copyright of AIDS Care is the property of Routledge and its content may not be copied or emailed to multiple sites or posted to a listserv without the copyright holder's express written permission. However, users may print, download, or email articles for individual use. 